\title{
Phantom validation of 4D flow: independent validation of vortex ring volume quantification using planar laser-induced fluorescence
}

Johannes Töger ${ }^{1,2^{*}}$, Sebastian L Bidhult ${ }^{1,3}$, Johan Revstedt ${ }^{4}$, Marcus Carlsson ${ }^{1}$, Håkan Arheden ${ }^{1}$, Einar Heiberg ${ }^{1,3}$

From 18th Annual SCMR Scientific Sessions

Nice, France. 4-7 February 2015

\section{Background}

Previous studies suggest that vortex ring formation in the left ventricle of the human heart is a sensitive marker of cardiac diastolic function and overall cardiac health [1]. However, measurement of quantitative vortex ring parameters using $4 \mathrm{D}$ phase contrast magnetic resonance (4D PC-MR) has not previously been validated. Therefore, the purpose of this study was to validate

a) Vortex tank - 2D view

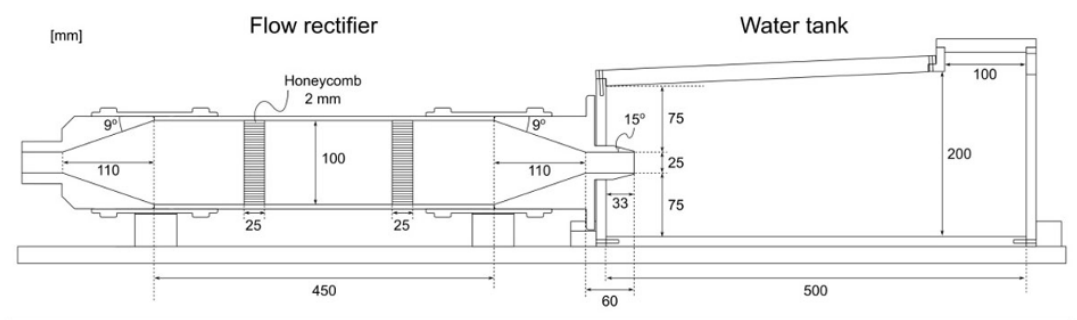

b) Vortex tank - 3D view

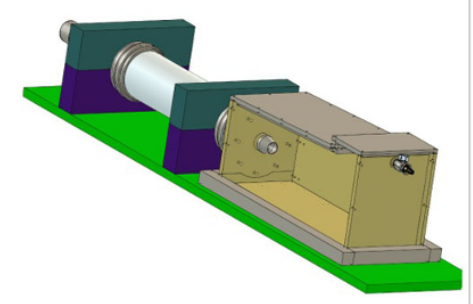

c) Pump design

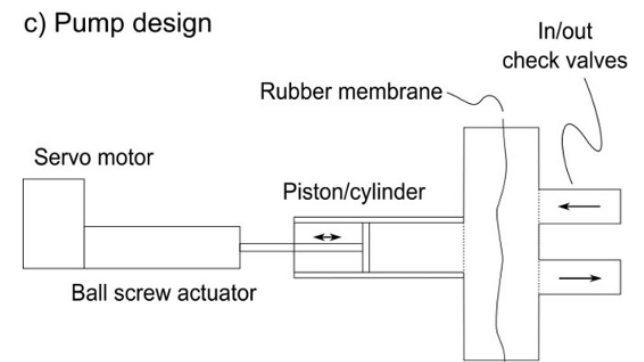

Ball screw actuator

Figure 1 Design and construction of the vortex ring flow phantom. a) $2 \mathrm{D}$ view of the flow rectifier and vortex ring tank. All measures are in millimeters $(\mathrm{mm})$. b) 3D view of the flow rectifier and vortex ring tank. c) Pump design. A servo motor powers a ball screw linear actuator, which in turn moves a piston-cylinder apparatus. A rubber membrane separates the flow medium from the pump to prevent abrasive particles from entering the piston/cylinder apparatus.

${ }^{1}$ Cardiac MR group Lund, Dept. of Clinical Physiology, Lund University, Lund,

Sweden

Full list of author information is available at the end of the article

(c) 2015 Töger et al; licensee BioMed Central Ltd. This is an Open Access article distributed under the terms of the Creative Commons 


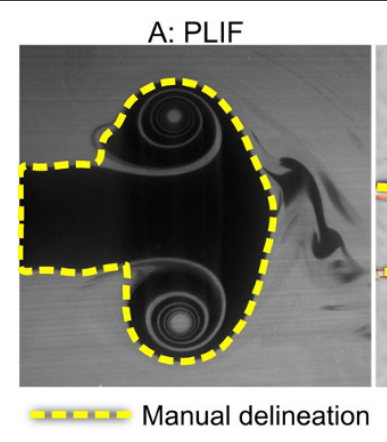

B: 4D PC-MR, LCS

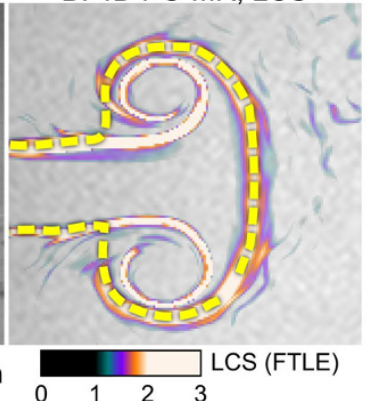

C: Validation

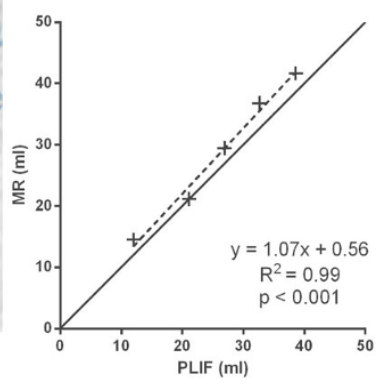

Figure 2 Data analysis in PLIF and 4D PC-MR images and quantitative results for vortex ring volume (VV). Panel A: Analysis of PLIF images. Panel B: Analysis of 4D PC-MR data using Lagrangian Coherent Structures (LCS). Panel C: Comparison of vortex ring volume (W) at the five pump settings.

measurement of vortex ring volume (VV) by $4 \mathrm{D}$ PC-MR using planar laser-induced fluorescence (PLIF) as the reference standard in a phantom setup.

\section{Methods}

We constructed a pulsatile pump and a water tank with a $25 \mathrm{~mm}$ nozzle (Figure 1), and five different pump settings with different pulse volumes and velocities were used. PLIF was performed using the fluorescent dye Rhodamine 590 (Rhodamine 6G, Exciton Inc., Ohio, USA) excited using a $532 \mathrm{~nm} \mathrm{Nd:YAG} \mathrm{laser} \mathrm{in} \mathrm{a} 1 \mathrm{~mm}$ vertical laser sheet. Images were acquired $400 \mathrm{~ms}$ after pump initiation, i.e. after complete vortex ring formation. Nozzle stroke volumes were measured using $2 \mathrm{D}$ PC-MR (voxel size $2.4 \times 2.4 \times 6 \mathrm{~mm}$, VENC $50 \mathrm{~cm} / \mathrm{s}$ ). $4 \mathrm{D}$ PC-MR was acquired at $1.5 \mathrm{~T}$ with $3 \times 3 \times 3 \mathrm{~mm}$ voxels and $50 \mathrm{~ms}$ temporal resolution. Vortex ring volume (VV) was quantified in PLIF by manual delineation (Figure 2A), and in 4D PC-MR data using manual delination of Lagrangian Coherent Structures (Figure 2B), a method for analysis of flow data that enables detection of the vortex ring boundary [2].

\section{Results}

Stroke volumes ranged from $12-37 \mathrm{ml}$. Vortex ring volume (VV) showed excellent agreement between PLIF and 4D PC-MR (Figure 2C, $\mathrm{R}^{2}=0.99$, bias $2.4 \pm 1.5 \mathrm{ml}$ ).

\section{Conclusions}

This study shows that vortex ring volume (VV) can be reliably quantified using 4D PC-MR.

\section{Funding}

This study was supported by Swedish Research Council grants VR 621-2005-3129, VR 621-2008-2949, and VR K2009-65X-14599-07-3, National Visualization Program and Knowledge Foundation grant 2009-0080, the Medical
Faculty at Lund University, Sweden, the Region of Scania, Sweden and the Swedish Heart-Lung Foundation.

\section{Authors' details}

${ }^{1}$ Cardiac MR group Lund, Dept. of Clinical Physiology, Lund University, Lund, Sweden. ${ }^{2}$ Numerical Analysis, Centre for Mathematical Sciences, Lund University, Lund, Sweden. ${ }^{3}$ Department of Biomedical Engineering, Faculty of Engineering, Lund University, Lund, Sweden. ${ }^{4}$ Department of Energy Sciences, Lund University, Lund, Sweden.

Published: 3 February 2015

\section{References}

1. Gharib M, Rambod E, Kheradvar A, Sahn DJ, Dabiri JO: Optimal vortex formation as an index of cardiac health. In Proc Natl Acad Sci. Volume 103. U S A; 2006:6305-8.

2. Shadden SC, Dabiri JO, Marsden JE: Lagrangian Analysis of fluid transport in empirical vortex ring flows. Phys Fluids 2006, 18:047105.

doi:10.1186/1532-429X-17-S1-P38

Cite this article as: Töger et al:: Phantom validation of 4D flow: independent validation of vortex ring volume quantification using planar laser-induced fluorescence. Journal of Cardiovascular Magnetic Resonance 2015 17(Suppl 1):P38.

\section{Submit your next manuscript to BioMed Central} and take full advantage of:

- Convenient online submission

- Thorough peer review

- No space constraints or color figure charges

- Immediate publication on acceptance

- Inclusion in PubMed, CAS, Scopus and Google Scholar

- Research which is freely available for redistribution
Biomed Central 